\title{
Perspectives in Engineered Mesenchymal Stem/Stromal Cells Based Anti- Cancer Drug Delivery Systems
}

\author{
Darinka Gjorgieva Ackova ${ }^{1}$, Tatjana Kanjevac ${ }^{2}$, Lia Rimondini ${ }^{3}$ and Darko Bosnakovski ${ }^{1,3,{ }^{*}}$
}

${ }^{I}$ Faculty of Medical Sciences, University Goce Delcev, Štip, R. Macedonia, ${ }^{2}$ Faculty of Medical
Sciences, University of Kragujevac, Kragujevac, Serbia; ${ }^{3}$ Faculty of Medical Science Università del
Piemonte Orientale, Novara, Italy

Received: September 18, 2015; Accepted: October 30, 2015; Revised: October 30, 2015

\begin{abstract}
Understanding and apprehension of the characteristics and circumstances in which mesenchymal stem cells (MSCs) affect and make alterations (enhance or reduce) to the growth of tumors and metastasis spread is pivotal, not only for reaching the possibility to employ MSCs as drug delivery systems, but also for making forward movement in the existing knowledge of involvement of major factors (tumor microenvironment, soluble signaling molecules, etc.) in the process of carcinogenesis. This capability is reliable because MSCs present a great basis for engineering and constructions of new systems to target cancers, intended to secrete therapeutic proteins in the tumor region, or for delivering of oncolytic viruses' directly at the tumor site (targeted chemotherapy with enzyme prodrug conversion or induction of tumor cell apoptosis). MSCs as a crucial segment of the tumor surroundings and their confirmed tumor tropism, are assumed to be an open gateway for the design of promising drug delivery systems. The presented paper reviews current publications in this fieldwork, searches out the most recent patents that were published after 2012 (WO2014066122, US20140017787, WO2015100268, US20150086515), and tries to present the current progress and future prospective on the design and development in anti-cancer drug delivery systems based on MSCs.
\end{abstract}

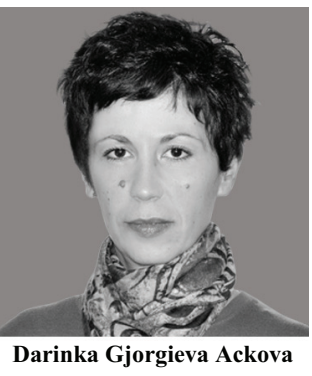

Keywords: Cancer therapy, cellular therapy, drug delivery, mesenchymal stem cells, oncolytic viruses, pro-drug, target therapy.

\section{INTRODUCTION}

Despite the prevailing efforts of impressive and long lasting attempts to create improvements in actions designed to achieve advances in therapy and methods for treating cancer, the long-established and classic therapies as radiotherapy and chemotherapy are still on the first line to control cancer. Several types of cancers do not response to ordinary used medical treatments. In the past, the main efforts and research in this field were focused only on cancer cells entity. Except malignant epithelial cells that have prime importance in cancer formation, the surrounding components or microenvironment consisted of diverse cell types; the extracellular medium and specific signaling molecules have a significant impact as well [1-3]. A selection of previously mentioned elements and their combination is crucial for cancer spread.

The transportation and distribution of drugs against cancer exactly to the tumor site even now is a great provocation in the plan of action to design effective cancer treatment. Mesenchymal stem cells (MSCs) as a crucial segment of the tumor surroundings and their confirmed tumor tropism, assume to be an open gateway for the design of promising drug delivery systems. Friedenstein et al. for the first time describe

*Address correspondence to this author at the Faculty of Medical Sciences, University "Goce Delcev" Štip, Krste Misirkov bb, 2000 Štip, R. Macedonia; Tel: +389 (0)70 516649; E-mail: darko.bosnakovski@ugd.edu.mk
MSCs as multi-potent mesenchymal stromal cells, very similar to fibroblasts and located in the bone marrow [4]. Depending on their morphology, MSCs are a heterogeneous population of cells and their characterization (description and recognition) is based on a combination of criteria as adherence to plastic, expression of CD73, CD90 and CD105, lack of haematopoietic cell markers such as CD34, CD45, CD19, CD11b, HLA-DR on the cell surface and the potential for multi-differentiation into osteoblasts, adipocytes and chondroblasts in vitro. Multipotent MSCs can be successfully isolated from human bone marrow, adipose tissue and Wharton's Jelly of umbilical cord $[5,6]$. Several studies have documented that MSCs derived from fetal tissue have more advantages than MSCs derived from adult tissue, as they can be isolated noninvasively and without ethical reservations and they possess active tumor-homing capacity [7]. From a large number of members in the stem cells class, MSCs are the first type to be employed in clinical practice, particularly in regenerative medicine and tissue engineering field, mainly in view of the fact that they possess the ability for large-scale proliferation, self-regeneration, multipotent differentiation and suitability for autologous transplantation. In this view, therapeutically advantageous features of MSCs are existing possibilities for easy isolation and acquisition, fast expansion in culture, feasibility of autologous transplantation and their significant paracrine effects $[5,6,8-10]$. In the course of the proliferation and differentiation processes, MSCs cooperate 
with other cells both through cell-cell interactions and paracrine signalizations (growth factors, cytokines, antifibrotic or angiogenic mediators) [11]. There are discrepancies in the reported data about the self-renewal ability of MSCs, that is, the ability to undergo numerous cell divisions while retaining their stem cell identity. This might be partially explained by the presence in tissues of diverse precursor types, heterogeneous in nature and origin of cells (that seem similar according to their in vitro characteristics) [12].

First-line targets for MSCs are sections of new stroma formation where the site of hematopoiesis, inflammation, and/or injury belongs. Because of this property, MSCs can contribute to reparative processes in different pathological conditions, including cancer. Since the tumor-homing capacity of MSCs was discovered, the application of specific geneengineered MSCs has held great potential for anticancer therapies. Accumulation and persistence of MSCs in solid tumors have been reported [13-17] and also demonstrated in experiments with a number of human cancer cell lines [2, 1823]. This anticancer dual-targeted strategy is based on MSCs' capacity of tumor-directed migration and in situ expression of tumor-specific anticancer genes.

MSCs provided by exogenous sources also have preferences to accumulate and integrate into the tumor tissue. This important feature is shown in in vivo experiments with tumor-bearing animal models. The assembly of molecules secreted by tumors, as for example monocyte chemotactic protein-1 secreted by primary breast tumors [24], stimulates the migration of MSCs and is liable for functional response with different classes of receptors located on the MSCs surface $[17,24,25]$. This directed migration and specific incorporation of MSCs at tumor target site was observed in studies with cell cultures in vitro and animal models in vivo. Those tumor tropism abilities are consistent, and also independent of cancer type and delivery route of MSCs. All these characteristics of MSCs are suggested as a tool which gives good grounds for delivering various biological agents with the expectance of great potential for anti-cancer therapy [23, 26]. Concerning, at some points, the inconsistent and conflicting results about MSCs function in tumor microenvironment, the effects over inhibition and/or stimulation, and the proliferation of cancer cells obtained from several studies, there are still some scientific disagreements. In general, results leading to the proposal of two major elements are likely to be correlated with the significant impact on cancer development. The first element is bidirectional cell communication, and the second one is the possibility of suppressive outcomes over the immune system which at the same time make tumor genesis possible [16, 27-29]. Almost certainly, this bidirectional cellular communication is a crucial stage in tumor progression (Fig. 1).

\section{MSCS ENGINEERED AS ANTICANCER DRUG DE- LIVERY SYSTEMS}

Concerning the persisting option for carrying therapeutic agents straight at the targeted tumor by the application of MSCs as carriers and consequently secure raised concentrations of these agents locally [30], there are many research groups working on different aspects of the possibility to involve these cells as drug delivering systems for therapeutic proteins, replicative oncolytic viruses, or for enzyme prodrug conversion (Table 1). Therapeutic proteins which raised great interest because of the possibility to be managed by MSCs are interferon $\alpha(\operatorname{IFN} \alpha)[31,32]$ and $\beta$ (IFN $\beta)[23,31-34]$, interleukin (IL) 12 [35], cytokine IL2 [36] and chemokine CX3CL1 (fractalkine) [37].

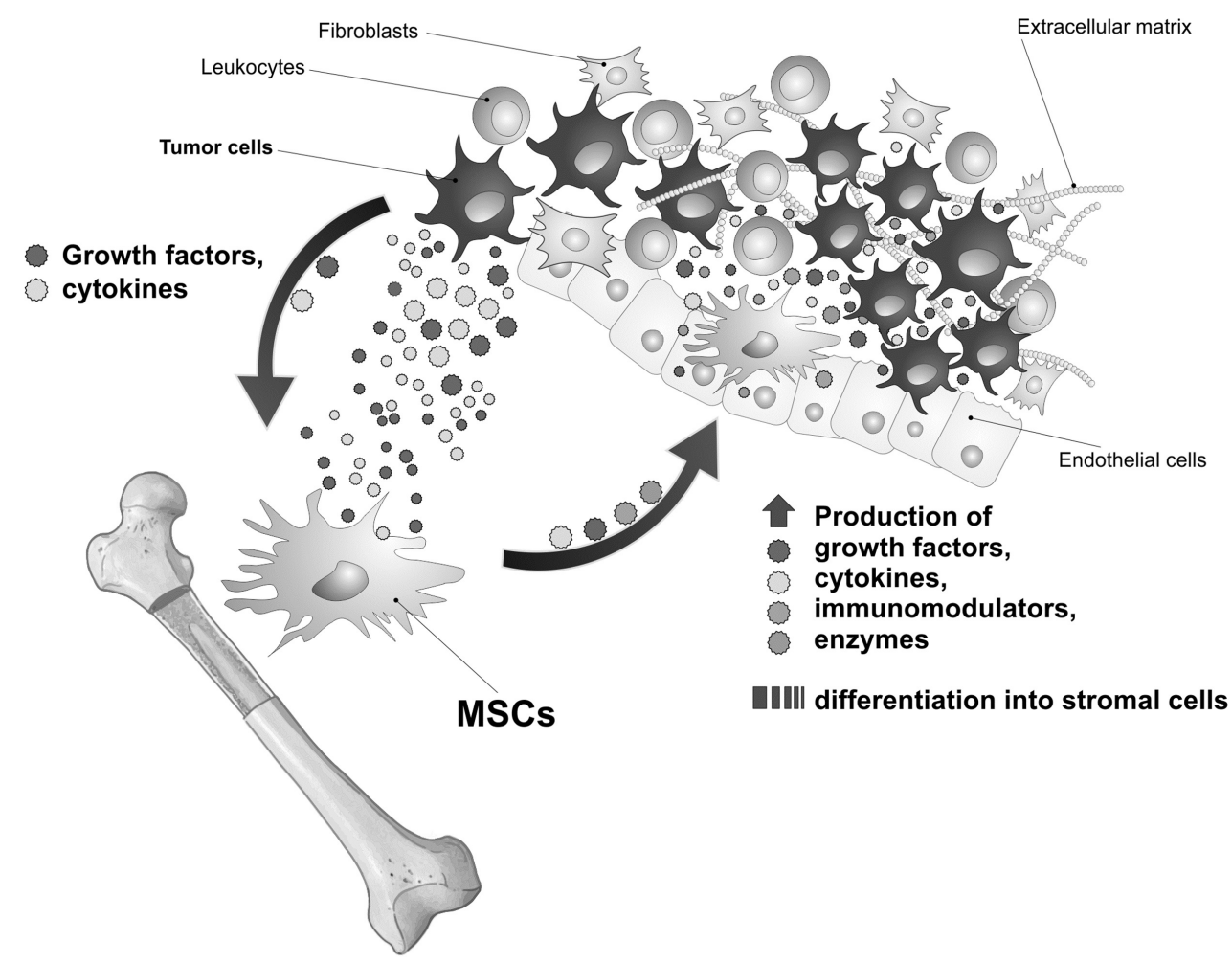

Fig. (1). Bidirectional cellular communication among MSCs and tumor cells. 
Table 1. MSCs used as Drug Delivery Vehicles for Anticancer Agents.

\begin{tabular}{|c|c|c|}
\hline Anticancer Agent that can be Delivered & Cancer Model Investigated & Cited References \\
\hline \hline Interferon $\alpha$ & Glioma, cancer of prostate, lung and pancreatic tumors & {$[23,31-34,38]$} \\
\hline Interferon $\beta$ & Melanoma lung metastasis model & {$[32,41]$} \\
\hline Interleukin 12 & Lung and breast cancer models & {$[35,42,43]$} \\
\hline Interleukin 2 & Glioma & {$[36,44]$} \\
\hline Chemokine CX3CL1 & Metastatic cancer model & Glioma \\
\hline Antiangiogenic agents & Lung and breast tumor, metastatic cancer model & {$[50,52-54]$} \\
\hline Oncolytic virus & Melanoma (mouse), glioblastoma cells (human), pancreatic \\
\hline carcinoma, colon tumors & {$[59-64,67]$} \\
\hline Tumor necrosis factor-related apoptosis inducing ligand & Brain tumors, lung cancer, glioma, metastatic cancer model & {$[19,70-72]$} \\
\hline
\end{tabular}

There are a number of studies of effects of IFN $\alpha$ and IFN $\beta$ incorporated into systems delivered by MSCs over tumor growth showing the inhibitory effect of IFN $\alpha$ and its usefulness as adjuvant therapy for the elimination of micrometastasis in risk patients [38], while anticancer effect of IFN $\beta$ is determined as apoptosis-stimulation effect $[39,40]$ and only toxicity observed after its systemic administration limits its clinical applications [41]. This undesired effect of IFN $\beta$ can be reduced by using MSCs as carriers for targeted delivery. One study by Ren et al., 2008 [32] is representative where mouse MSCs genetically engineered to express human IFN $\beta$ coding sequence in prostate cancer model are used.

IL-12 (a heterodimeric glycoprotein) [35, 42, 43] or IL-2 $[36,44]$ secreted by MSCs initiates an immunoreaction and stimulates infiltration of inflammatory cells at the tumor site, which is a way to avoid systemic toxicity at the same time [45]. There is a study performed by Chen et al. in 2006, where genetically modified MSCs for secretion of IL-12 of mouse origin were evaluated according to their anti-cancer potential in three types of tumor models in experimental animals [35]. In a similar study, Stagg et al. [44] showed that in the case of melanoma cancer model investigated, when MSCs producing IL-2 are mixed with B16 cells, delayed tumor growth is achieved in $90 \%$ of examined cases.

Different molecules can be a target site for antiangiogenic therapy due to their engagement in tumor-mediated angiogenesis [46] which gives possibility for use of MSCs expressing antiangiogenic factors (thrombospondin (TSP)-1) to inhibited tumor development [47-49].

One way of modification of MSCs is the possibility of releasing conditional replicative oncolytic viruses [50-53]. When oncolytic viruses are systemically delivered, the host immune system is responsible for the defense, which results in the elimination of the circulating viruses before they can reach the tumor site. Autologous MSCs are not recognized as foreign by the host immune system, and those incorporated oncolytic viruses can reach the tumor without systemic limitations [54]. The most extensively used one is the oncolytic virus Adenovirus serotype 5 (Ad5). The disadvantage of its use is the need for internalization into host cells [55]. Another virus with broad application where engineered MSCs act as carriers is Herpes simplex virus type 1 (HSV-1). To control Ad5's limitations, modifications of adenoviruses have been researched with great attention put on chemical conjugation [56], fiber-modification of adenoviruses [57], etc. Lately, Menotti et al., have investigated possible modifications and designed HER2 (human epidermal growth factor receptor 2)-retargeted HSV-1 vectors by using the process of conjugation with a single-chain antibody (scFv) [58]. Additional investigations for new carriers of oncolytic viruses are still going on.

MSCs are used as vehicles for targeted anticancer therapy by using the mechanism of enzyme prodrug conversion [5964]. The basic of this mechanism is the conversion of a prodrug (which has low toxicity) to a high toxic metabolite (produced only at tumor site) where the reaction is catalyzed by enzymes $[65,66]$. In this way systemic toxicity of chemotherapy is kept on minimum because the concentration of the drug in blood is on the possible lowest level [67]. Generally, the most applicable system is the cytosine deaminase (CD)-5fluorocytosine (5-FC) (enzyme CD converts the relatively less toxic prodrug 5-FC to toxic metabolite 5-fluorouracil (5-FU)).

In experiments with MSCs expressing tumor necrosis factor-related apoptosis inducing ligand (TRAIL) (a type II membrane ligand from Tumor Necrosis Factor (TNF) family) anticancer effects are also detected, probably by induction of apoptosis [68-74]. This effect was reported in case of prostate cancer investigated [19], and also in other experimental cancer models (glioma and lung cancer). How tumortropic capability of MSCs is adjunct by the engineering process remains largely unknown and investigations are still going on.

\section{RECENTLY PUBLISHED PATENTS (2012-PRESENT) CONCERNING MSCS AS DELIVERY VEHICLES FOR ANTICANCER DRUGS}

The results and conclusions throughout the investigations about the relationships MSCs-tumor cells obtained from sci- 
entific research are not consistent, and there are multiple factors proposed to have contributed to this. Maybe the heterogeneity between MSC populations is one of the prime factors that must be taken into consideration. The recently published patents reviewed in the presented manuscript, in general, proposed MSCs as promising new drug delivery systems.

Pittenger and Aggarwal are the authors who, in a patent published in 2011, demonstrate various applications of MSCs and their interactions with dendritic cells (DC1 and DC2), effector T-cells (Th1 and Th2), and NK cells [75]. The authors find that MSCs stimulate DCs to produce IFN $\beta$, which promotes tumor suppression. The same authors continued their work and in 2014 published another invention which is an updated version of the previous one [76] (Table 2).

In a recently published patent in 2013, Crawford and Southgate [77] also described uses of multi-potent stem cell. In this invention, methods for purification of stem cells population from synovial fluid and blood are provided. These cells are embryonic in character, and in contrast to other adults stem cells (which require a longer period of culture before expression), express key embryonic transcription factors within a few days of isolation. These cells can proliferate and differentiate into all three germ layers (mesoderm, ectoderm and endoderm). In another aspect, the invention provides methods for forming adipocytes, muscle cells, neural cells, hepatocytes, endothelial cells, and hematopoietic cells. Methods of treatment of different diseases or conditions are also given. In the patent also published in 2013 by Brodie and Slavin, in vitro modeling of MSCs and cell-based therapy of human brain diseases are given [78].

More recently, in 2014, Peled and Steinhardt's patent [79] was published also concerning methods of culturing and expanding MSCs. The novelty in the presented method is culturing a population of the MSCs in a medium where the aryl hydrocarbon receptor antagonist is included. Another similar research is the patent published by Sabbadini in 2013, where direct inhibitors of lysophosphatidic acid (LPA) are used as a component in the system for stem cell therapy [80]. Very recently, in 2015, in the patent published by Lim and Lye [81], a method of deriving MSCs is also described. In contrast to methods previously used, this new method provides a clinically relevant and reproducible protocol for isolating similar or homogenous MSCs populations from differentiating embryonic stem cell (ESC) colony into cells. In order to obtain MSCs, the ESCs are propagated in a serum free medium containing fibroblast growth factor 2 . The novelty of the presented protocol is that serum, mouse cells and genetic manipulations are not required, manipulations performed require less time and the protocol is highly scalable.

In a patent published in 2012, the author presented related therapies where the application of MSCs is an option [82]. Research is focused on the invention of a method whose application will avoid troubleshooting occurring in stem cell therapy in adult patients where contradictions about the prediction of the behavior of transplanted stem cells in a patient's body are still existing. The prime issue in the proposed method is the incubation of isolated MSCs with Tolllike receptor ligand (TLR). With in vitro studies on human cancer cell lines the divergent effects of MSC1 (stimulated) and MSC2 (non-stimulated) are shown. The author of the above mentioned patent, Betancourt, A.M., in 2014 published another patent extension of the first one, where TLR ligand is selected from aminoalkyl glucosaminide-4-phosphates, interferons, TNF, GM-CSF, lipopolysaccharide (LPS), or combinations thereof [83]. TNF (formerly referred as TNFalpha), as a strategy for treating tumors, is a point of interest in the invention published by Cheng et al. [84]. TNF is a cytokine with well-known anticancer properties and is used as an agent for solid tumors treatment. The authors provided a method for using engineered MSC as a vehicle for delivering secreted tissue necrosis factor-RGD4C fusion polypeptides for reducing side effects of TNF (fever and decreased blood pressure) before therapeutic doses can be reached. In addition, to monitor the localization and viability of the engineered MSCs in vivo after administration in animalrecipient, a lentiviral vector was constructed with dual reporter gene mrfp-ttk included in it. Genetically modified MSCs can include a nucleic acid sequence operably linked to a gene expression promoter and encoding the heterologous fusion polypeptide, which includes a tissue necrotic factor region and an integrin-binding region. An additional part of this work is a method for modulation of the proliferation of target tumor cells by a delivered population of MSCs. The step of monitoring the distribution of the genetically modified MSCs in the recipient (animal or human) can be detected by bioluminescence, fluorescence, MRI, or PET scanning [84]. The interest for TNF is continuously present and one very recently published invention also describes the use of this cytokine [85]. The invention presents genetically engineered MSCs as a vehicle for delivering tissue necrosis factor-RGD4C fusion polypeptides intended for cancer treatment. This strategy reduces the side effects of TNF.

Methods of generating and expanding the human embryonic-mesenchymal stem cells (hES-MSCs) are given in two patents of Wang and $\mathrm{Xu}$, just recently published [86]. These cells are useful for the prevention and treatment of $\mathrm{T}$ cells related autoimmune disease, as well as for delivering agents across blood-brain and blood-spinal cord barrier. The hESMSCs may be in the form of a single cell, cell culture, a solution or a pharmaceutical preparation. The agent included in it is for the treatment, prevention or diagnosis of a disease or injury and can be, but is not limited to drugs, proteins, DNA, RNA, and small molecules. In one embodiment, a kit comprises hES-MSCs and cell delivery carriers are provided. In the second patent, in addition, conditions for the development of embryonic stem cells through an intermediate differentiation of trophoblasts and differentiation of trophoblasts into the hES-T-MSCs are given (Table 2). Solutions and pharmaceutical preparations which include hES-T-MSCs, methods of making the hES-T-MSCs and their uses are also given.

Methods for diagnosis, prevention, treatment, or monitoring of brain tumors are given in the patent from 2013 of Chang et al. [87]. The patent relates to a gene therapy composition for transferring a therapeutic gene, a marker gene, or their products to the cells expressing IL-8 or growthregulated protein alpha (GRO- $\alpha$ ) and it induces tropism of Umbilical Cord Blood-Derived Mesenchymal Stem Cells (UCB-MSCs). UCB-MSCs are genetically modified to trans- 
fer a therapeutic agent inhibiting brain tumor cells growth or a therapeutic gene (an antitumor gene, a prodrug converting enzyme gene, or oncolytic virus), or a product of it. An important embodiment of the presented patent is the composition of a kit for treating brain tumors where the expression vector of a prodrug converting enzyme gene, UCB-MSCs and a prodrug anticancer drug are included. The prodrug converting enzyme gene can be selected from a cytosine deaminase gene and a CYP2B1 gene. Also, a separate embodiment of the same patent is the composition for diagnostic or monitoring of brain tumors treatment which includes UCB-MSCs, labeled with a detectable marker. A marker can be selected between luciferase-containing enzyme-based fluorescent detector or Tat peptide-derivatized magnetic nanoparticles. The same approach, application of magnetic nanoparticles for labeling MSCs, is also an object of interest in another invention [88] where a recently developed method that exploit MRI to follow MSCs labeled with iron oxide nanoparticles is presented. The use of iron oxide labeledMSCs is encouraged for the target delivery of anticancer agents and also for the possibility to damage tumor cells by persistent option for thermotherapy. The above mentioned authors, Chang et al. [87], in the context of the use of UCBMSC, again in 2013 studied stem cells having an effective tropism for tumors and published another patent related to a pharmaceutical composition comprising UCB-MSC. In this composition the UCB-MSC functions as a carrier for gene therapy (prevention and treating) for brain tumors [89]. The inventors performed an experiment with introducing a gene coding green fluorescent protein (GFP) into UCB-MSCs. According to the presented invention, a pharmaceutical composition (kit) containing UCB-MSC can be used to diagnose, prevent, and treat diseases related to cells expressing IL-8 or GRO- $\alpha$ or brain tumors. Many research groups as their focus of interest have cancer vaccines and their capability to target tumors and make differences between neoplastic and healthy cells $[90,91]$. In an invention just lately published, in 2014, cancer vaccines are proposed to be used together with chemotherapy, for example [92] (Table 2).

As different epigenetic (cell proliferation, inhibition of apoptosis and induction of angiogenesis) and genetic (activation of oncogenes and inactivation of tumor-suppressor genes) factors can be involved in cancer initiation, in an invention published in 2013 by Cohen, pharmaceutical compositions and methods for treatment of cancer or other proliferative diseases are evaluated [93]. The prime position in the invention is taken by intra- and extracellular components of stem cells, which can be a rich source of biomolecules associated with epigenetic reprogramming, or alteration of the malignant nature of the cancer cells.

Similarly, the recent published invention of Habib and Gordon [94] provides an apoptosis-modulating cell-free composition which is the extracellular medium of a stem cell and therapeutic uses thereof. The inventors examined a certain class of stem cells, known as "OmniCytes", which could be used as vehicles for delivering drugs to cancer cells. Cancer cell lines were treated with a pro-apoptotic agent such as staurosporine, cisplatin or paclitaxel and cultured with OmniCytes. When an experiment was made with Transwell system (allows the exchange of soluble factors, but prevents cell-cell contact), the effect was secretion of one or more factor(s) from OmniCytes that potentiated the effect of the pro-apoptotic agent. This apoptosis-modulating factor was proposed for use in therapeutic applications of hyperproliferative disorders, particularly cancer. When non-cancerous cells were exposed to a pro-apoptotic agent and OmniCytes in a Transwell assay, the secreted factor had a protective effect, reducing the number of cells which underwent apoptosis. The protective effect on non-cancerous cells is a particularly useful part of this invention, because in the treatment of cancer healthy cells will be spared. It is likely that other types of stem cells, such as HSCs and MSCs, can also excrete the factor and are suitable types of stem cells from which the factor(s) may be isolated and used to prepare a conditioned extracellular medium [94]. Similar to patents described above one type of intra- or extracellular components of stem cells, particles, which may comprise a vesicle or an exosome secreted by MSCs are used in a patent published in 2015 [95]. The authors show that these particles possess biological properties of a MSC and they proposed the use of conditioned medium containing them for possible: 1) cardioprotection effect and 2) treatment of a group of diseases as bone marrow disease, skin disease, degenerative disease and cancer.

Suicide genes have become known as an attractive alternative therapy for the treatment of different resistant and complex cancer types. Suicide genes from non-human sources have emerged as an attractive approach to the treatment of brain tumors. MSCs expressing a suicide gene show excellent and highly selective anticancer effects (conversion of a prodrug to an anticancer agent at the cancer site) as in the case of $\mathrm{CD}$ as suicide gene which converts 5-FC to cytotoxic 5-FU killing neighboring cells (bystander effect). 5-FU itself is cytotoxic when it is directly administrated. But, when a combination of a suicidal gene and prodrug of 5-FU, namely 5 -FC is administered, 5 -FU is produced selectively at tumor cells $[96,97]$. This possibility presented in the work of Chang et al., 2010 [98] is explained as being applicable on humans, ex vivo therapeutic modality, wherein by using bacterial CD-expressing MSCs, the recurrence of malignant brain tumors can be effectively suppressed. Several preclinical parameters, critical for this therapy, including the total $\mathrm{CD}$ activity and 5-FC concentration, are assessed in this study.

Another standard model for use of a suicide gene is herpes simplex type 1 thymidine kinase (HSVTK), which converts non-toxic gancyclovir into a toxic metabolite [59]. Bystander effects were observed after intratumoral administration of MSCs and intraperitoneal injection of gancyclovir, with a significant fraction of mouse model animals surviving long-term period [99]. A novel and worth mentioning aspect of this study was the use of imaging techniques PET and MRI to track the injected cells and the possibility of determinate the therapeutic efficacy. The translation of this therapeutic strategy to clinic practice may be questionable, but there is no doubt about the usefulness of developing molecular imaging techniques to track cells in vivo.

The same suicide gene, as indicated above, is used in the patent published in 2012 by Nelson, which provides a method for treatment of pancreatic cancer through i.v. 
Table 2. Patents Concerning MSCs and their Use as Anticancer Drug Delivery Systems (Published 2012-Recent).

\begin{tabular}{|c|c|c|c|}
\hline Patent/Year & Inventor(s) & Reference & Description of the Invention \\
\hline US20120087901 (2012) & Nelson, $\mathrm{P}$. & {$[100]$} & Engineered MSCs and methods of using them to treat tumors \\
\hline WO2012071527 (2012) & $\begin{array}{l}\text { Boyan, B.D., Schwartz, Z., Lee, C.S.D., } \\
\text { Leslie, S.K., Kinney, R.C. }\end{array}$ & [104] & Protein delivery from stem cell microcarriers \\
\hline US20120263685 (2012) & $\begin{array}{l}\text { Ra, J.C., Kang, S.K., Woo, S.K., Youn, H.Y., } \\
\text { Lee, H.W., Seo, K.W. }\end{array}$ & [107] & hASCs as anti-tumor composition \\
\hline WO2012106281 (2012) & Shah, K. & [114] & Multimodal TRAIL molecules \\
\hline US8574567B2 (2013) & Crawford, K.D., Southgate, C. & {$[77]$} & Uses of multipotent stem cell \\
\hline US20130189189 (2013) & Chang, J.W., Kim, D.S., Yang, Y-S., Oh, W. & [87] & $\begin{array}{l}\text { Using UCB-MSCs for diagnosis, prevention, or treatment of } \\
\text { brain tumors }\end{array}$ \\
\hline US8506948B2 (2013) & Chang, J.W., Kim, D.S., Yang, Y-S., Oh, W. & [89] & Using UCB-MSCs for diagnosis, prevention, or treatment \\
\hline US20130052272 (2013) & Cohen, S. & [93] & Uses of cell extracts for treatment and prevention of cancer \\
\hline US20130171115 (2013) & Li, G., Lee, Y.W., Lau, P.Y. & {$[101]$} & Cell-mediated gene therapy using MSCs expressing a suicide gene \\
\hline WO2013106774 (2013) & Orrichio, E., Wendel, H-G. & {$[102]$} & Cancer-specific suicide gene \\
\hline US2014016776 (2014) & Aggarwal, S., Pittenger, M.F., Varney, T. & [76] & Uses of MSCs \\
\hline WO2014066122 (2014) & $\begin{array}{l}\text { Prockop, D.J., Lee, R.H., Yoon, N., Reneau, } \\
\text { J., Berkowitz, B.A. }\end{array}$ & [108] & Activated MSCs for tumor treatment \\
\hline US20140086907 (2014) & The General Hospital Corporation & {$[115]$} & Multimodal TRAIL molecules \\
\hline US20140369979 (2014) & Sung, Y.C., Kim, S.W., Kim, S.J., Park, S.H. & [116] & $\begin{array}{l}\text { TRAIL and HSV-TK suicide genes, and anticancer stem cell } \\
\text { therapeutic agent }\end{array}$ \\
\hline WO2015089280 (2015) & Shah, K. & {$[117]$} & MSCs delivered oHSV and TRAIL-oHSV \\
\hline US20150197725 (2015) & Lim, S.K., Lye, E. & [81] & Method for deriving MSCs \\
\hline WO2015100268 (2015) & Chang, A., Nolta, J. & {$[118]$} & Engineered MSCs for secretion of antibody-like molecules \\
\hline US20150190430 (2015) & Lim, S.K. & {$[95]$} & MSCs particles \\
\hline US20150086515 (2015) & Cheng, Z., Chen, K., Chen, X. & [85] & MSCs delivering tissue necrosis factor-RGD4C fusion polypeptides \\
\hline
\end{tabular}

injected engineered MSCs (CD34- modified cells) [100]. In 2013, Li et al. published their invention concerning cellmediated gene therapy for cancer using MSCs transfected also with a suicide gene [101]. The method has a few steps: 1) introducing a population of MSCs (expressing a suicide gene) into the subject; 2) allowing enough time for the mi- gration of MSCs from the site of administration to the site of the tumor; and 3) introducing a prodrug which will be converted to toxic drug, lethal for tumor cells. A prototype suicide gene is thymidine kinase, and the prodrug is gancyclovir. Possibilities of using other models of suicide genes (CD, purine nucleoside phosphorylase (PNP), cytochrome 
p450 enzymes (CYP), carboxypeptidases, etc.) and prodrugs (5-FC, 6-methylpurine deoxyriboside (MEP), fludarabine (FAMP), cyclophosphamide, methotrexate $\alpha$-peptides, etc.) are also given. The invention also provides a kit formulation for treating a tumor. The improvements given in this patent are well-characterized stem cell properties, tumor tropism, low immunogenicity, and proliferative capacity suitable for bulk production. Another model of suicide gene used in gene therapies of cancer is specified in a patent also from 2013, published by Orrichio and Wendel [102]. They provide a method for using pluripotent and multipotent stem cells that have be modified to include an inducible cancer-specific suicide gene that selectively kills stem- or progenitor cells derived cancerous cells with no effect on other noncancerous cells.

In a great number of experiments, adenoviruses and their modified versions (incorporation of different amino acid sections) were used as delivery vectors of viral load specific to the tumor site $[50-53,103]$. One of the difficulties in the treatment of conditions such as cancer is the need to deliver large quantities of the therapeutic agent for extended periods of time. Boyan et al., in the invention published in 2012, present an approach of using MSCs as micro carriers for protein delivery [104].

MSCs have the property to integrate into the tumor stroma which gives them the possibility to deliver a necessary dose of biological agents with short half-life or wellknown toxicity [23]. One of the first studies in this field is the patent published by Studeny et al. [105] where MSCs or stromal cell precursors are genetically modified to produce a therapeutic agent (IFN $\alpha$, IFN $\beta$ or similar). Implementation of MSCs expressing IFN $\beta$ results in decreased tumor mass and prolonged animal survival (shown in tumor-bearing experimental animals). Regional secretion of IFN $\beta$ is preferred because it decreases systemic toxicity [33]. This regional secretion is also preferred for a therapeutic effect of IL-12 or IL-2 where an immunoresponse and stimulation of infiltration of inflammatory cells at the tumor site are observed [36, 42-44]. The aim of the investigation of Von Laer and Heimann, 2011 [106] was to develop a highly potent oncolytic viral gene transfer system for therapeutic genes for therapy of highly malignant brain tumors (as gliomas) and different types of solid tumors. Vesicular stomatitis virus (VSV) pseudotype vector is used for gene coding for a glycoprotein (GP) of the lymphocyte choriomeningitis virus (LCMV). VSV-LCMV-GP pseudotype vector includes at least one therapeutical transgene which can be a suicide gene (HSV-TK, CD, FKBP-caspase-9) or an immunostimulatory gene (encoding IL-2, IL-4, IL-12, etc.) and a virus producing cell produces a VSV virion pseudotyped with LCMV-GP. The virus producing cell is an adult stem cell, for example MSC. The subject of the invention is also the use of VSVLCMV-GP system for the preparation of a pharmaceutical composition for solid tumors therapy.

The work of $\mathrm{Ra}$ et al., 2012 [107] is directed at preventing cancer (providing anticancer activity) by using adult stem cells to activate the immune system. This adult stem cell may be derived from adipose tissue or epithelial tissue, and preferably MSCs are used. These cells secrete specific cytokines that activate the immune system and show the treating cancer effect by inhibition of the expression of cancer cells chemokines. The pharmaceutical composition of the presented invention is administered in a therapeutically effective amount at the early stage of the cancer diseases, if possible.

Prockop et al., 2014 [108] in their experimental work tested the hypothesis that activated human MSCs (hMSCs) are tumor suppressive because of the fact that hMSCs activated with TNF- $\alpha$ expressed both TRAIL and Dickkopfrelated protein 3 (DKK-3). It was observed that DKK-3 expression was increased upon exposure of hMSCs to TNF- $\alpha$ in animal tumor models. The applicants of the patent discovered that the activated MSCs express increased amount of agents that inhibit, prevent, or destroy the tumor growth and furthermore, that cross-talk between activated MSCs further increased the expression of TRAIL and DKK-3. The activated MSCs can be administered in the amount from $10^{3}$ to $10^{9}$ cells depending on age, weight, and sex of the patient, the type and location of the tumor being targeted, in conjunction with an acceptable pharmaceutical carrier, and in combination with at least one chemotherapeutic agent (doxorubicin, cisplatin, 5-FU, irinotecan, etc.).

MSCs secreting TRAIL have been tested in different models of cancers in vivo, resulting in notable anti-tumor effects $[19,68,71,72,88,109]$. Contrary to previously said, MSCs (similar to most other healthy cells) are unsusceptible to TRAIL-induced apoptosis [71]. In addition to this, in the TRAIL transfected adult MSCs, fetal-MSCs and umbilical cord matrix stem cells, there are almost undetectable levels of apoptotic pathway components (caspase- 8 and caspase-9) [110]. The application of this system (MSCs secreting TRAIL) has advantages over some of the other engineered MSC-delivery systems since there are almost no-detectable effects on non-cancerous tissues. Promising early results are obtained not only from the investigations with animal models, but also from clinical trials carried out currently [111-114].

In the patent published by Shah in 2012, the methods of implantation of therapeutically engineered MSC with antitumor agents directly into tumor sites after surgery was presented. MSC-TRAIL cytotoxic therapy showed highly effective results in inducing apoptosis and potent inhibition of brain tumor growth. It was advised that the TRAIL approach would significantly improve treatment outcomes [114]. In the invention published in 2014 [115] there is description of novel compositions comprising multimodal TRAIL agents and cells engineered to express such multimodal TRAIL agents. These cells can be encapsulated in a scaffold or matrix, and used in the treatment of disorders such as cancer. The multimodal therapeutic agents, such as multimodal TRAIL agents, are useful in combinatorial therapies with chemotherapy, radiotherapy, or surgical interventions. The activation of cell surface receptors, such as death receptors (DRs), by the multimodal therapeutic agents and cells expressing such agents (engineered stem cells), represents an attractive therapeutic strategy to promote apoptosis of tumor cells. The stem cells of interest for use with the compositions and methods comprising multimodal TRAIL agents described in the invention can be naturally occurring stem cells or "induced" stem cells. Stem cells can be obtained or generated from any mammalian species, including humans. In 
some embodiments of the compositions and methods described, a pharmaceutically acceptable composition for administration into a subject comprising a neural stem cell (but not limited only to this type of stem cells) and a multimodal TRAIL agent is given. Other vectors (herpes simplex virus vectors, SV 40 vectors, polyoma virus vectors, papilloma virus vectors, etc.) encoding a multimodal TRAIL agent are also proposed for usage. For example, there is an embodiment in the patent that describes stem cells engineered to produce the secreted multimodal TRAIL agents which can be administered intravenously and are expected to reach desired areas of the brain, such as the site of a glioblastoma [115]. A very new invention, also published in 2014, presents DNA cassette encompassing a nucleotide sequence encoding TRAIL, a suicide gene nucleotide sequence, a recombinant adenovirus, and a host cell (preferably stem cell) transduced with the recombinant adenovirus. This work gives a composition for treating cancer comprising the host cell and steps of administering this composition to a subject [116].

Concerning the possibilities for using genetically engineered MSCs with different properties (secretion of TRAIL, delivery of oncolytic viruses, delivery of biological agents, etc) it can be noted that in few very new inventions published just recently, in 2015, there are efforts to use combinations of above mentioned methods. The patent of Shah [117] describes the therapeutic efficacy of MSCs loaded with infectious oncolytic herpes simplex virus (oHSV) and its proapoptotic variant (oHSV-TRAIL). In vitro and in vivo mouse glioblastoma multiforme (GBM) model was used. It was found that this model mimics exactly the clinic scenario of GBM resection and efficacy of MSCs loaded with oHSV and variants of it are on site. The result was the induction of apoptosis in TRAIL and oHSV resistant GBM and increasing of mice survival. Other also very new approach for targeted cancer therapy is published in 2015 by inventors Chang and Nolta [118]. In this invention, the authors harness the intrinsic ability of MSCs to home into cancer cells and subsequently regulate the secretion of an antibody-like molecule (under a promoter regulation). The invention provides an isolated polynucleotide composed of: promoter of expression of the C-C motif ligand 5 (CCL5 promoter) operatively linked to a polynucleotide encoding $\mathrm{Fc}$ and hinge region of a human IgG CD44 variant 6 (CD44v6). These engineered MSCs for secretion of antibody-like molecules that specifically target the metastatic cancer variant CD44v6, because of controlled expression of the CCL5 promoter, are effectively able to initiate immune cells reaction and the complement cascade. Because cancer cells attract these engineered MSCs with specific action, metastatic process of cancer stem cells can be disrupted, which can lead to elimination of early cancer cell metastasis.

Table 2 summarizes recently published (2012-present) inventions related to this subject and presented in this paper. The different roles of MSCs in anticancer drug delivery systems with their key points are noted and summarized in Table 3.

\section{NEW FACTS RAISED CONCERNS ABOUT USE OF MSCS AS AN ANTICANCER THERAPY}

MSCs have the capability to home to the tumor site after systemic delivery which provokes great interest and signifi- cant progress in the anticancer research. Despite extensive investigations over the last few years, the influence of MSCs on tumor progression remains unclear because of contradictory results. There are studies reporting promotions of tumor progression and metastasis, while others record suppression of tumor growth [119]. Numerous animal model studies have documented the therapeutic potential of MSCs and their safety and efficacy in vivo. But the anti-cancer properties of MSCs in humans are controversial because of still incomplete and limited human studies performed on small number of patients. The proposed use of MSCs in cancer therapies provoke strong disagreement in scientific community, due to opposite results for MSC promotion of tumor vascularization, promotion of cancer progression and the invasive tendency of tumors previously reported [28, 120-122]. In this contest, Li et al., 2011, inform about the dual role of human MSCs in tumor cell growth in vitro and in vivo. It was found that in vitro human MSCs inhibited the proliferation of A549 (lung cancer) and Eca-109 (esophageal cancer) cell lines and caused G1 phase cell cycle arrest and apoptosis. On the other hand, human MSCs were also found to increase tumor formation and growth in experiments in vivo [123].

Tumormodulatory effects of MSCs are under consideration also, because there are studies in animal models showing the ability of MSCs to home to sites of tumor and suppress or stimulate tumor growth via antiapoptotic effect, tumor progression, metastasis, and drug-resistance of cancer cells [124-128]. For illustration, in some experiments inhibition of primary tumor growth was observed after co-injection of MSCs with tumor cells in models of Lewis lung carcinoma and B16 melanoma [129], whereas the co-culture of MSCs with breast cancer cells improved tumor cell proliferation [130]. In part, the role of IL-6 secreted by MSCs in promoting multiple myeloma proliferation begins to clarify with molecular studies that give suggestions about the underlying mechanisms [131]. In the study of Serakinci et al., in vivo assays were performed to investigate if externally administered hMSCs would engraft at the tumor sites and interact with the cancer cells [132]. Karnoub et al. [27], in the past few years, also demonstrated integration of MSCs into breast cancer stroma and increase of cancer cell metastasis by MSC-secreted chemokine CCL5-dependent signaling. Additionally, the interaction between the immune cells and MSCs needs to be studied in vivo because MSCs transplants in animal models proved beneficial for some diseases, but had no effect in others. Thus, consideration and understanding of the inter- and intra-relationships between MSCs and cancer is essential for the improvement and progress of anticancer therapies and clinical exploitation of MSCs.

Another tumor enhancing property of MSCs is their ability to suppress the immune system [133]. While this immunosuppressive characteristic of MSCs is a desired property for patients with immune disorders, this ambiguous nature of MSCs may cause harm to patients with cancer, as a suppressed immune system may encourage tumor growth.

In the case of peritoneal cancers, MSCs from bone origin have been reported to locate around the tumor and in the ascitic fluid and, at the same time, became unable to differentiate in different cell lineages (loos of multipotent ability). These cells are defined as being carcinoma-associated (CA- 
Table 3. Different Roles of MSCs used as Drug Delivery Vehicles for Anticancer Therapy.

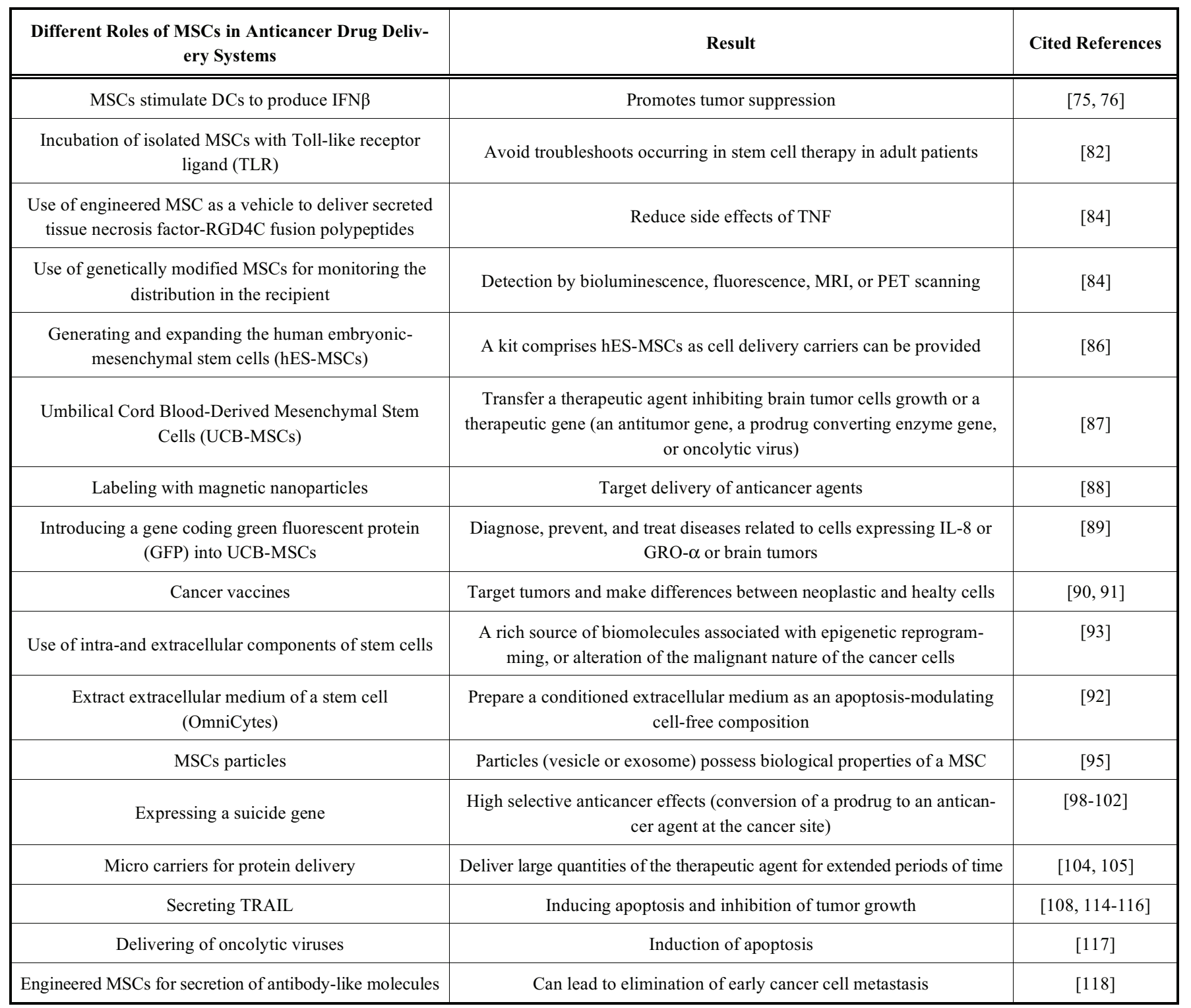

MSCs) and possess some characteristic markers of Carcinoma-Associated Fibroblasts (CAFs) [134, 135]. Tumorstroma interactions are considered a fundamental necessity for tumor development and progression. Interplay between tumor and non-malignant host cells (e.g., stromal cells, immune cells, activated endothelium) has also been described [136]. MSCs can be used in investigations of tumor microenvironment for anticancer drug development as is presented in the patent published in 2012 by Banerjee et al. [137]. The invention briefly presents an extracellular matrix bioscaffolds that includes CAF-like cells and tumor associated macrophages supporting tumor growth and formation, which can be used for the development of known or novel anticancer drugs. The CAF-like cells of the present invention may be differentiated from pluripotent HBMC, and such cells may include MSCs that are differentiated to exhibit one or more of the phenotypes. One method for MSC differentiation is by culturing the cells in tumor conditioned medium for about 1 to 30 days.
The invention of Derr et al., 2013 [138], provides new methods (signals as level of gene expression is) for classifying candidates for treatment with cancer associated mesenchymal cells, tumor initiating cancer cells, or cancer stem cell inhibitor treatment. In one embodiment, the cancer is characterized as including and enriched with cancer associated mesenchymal cells and the invention features administering an agent that inhibits or kills cancer associated mesenchymal cells or cancer stem cells based on the characterized gene expression profile.

There are recent findings that MSCs can be involved in the drug resistance development due to the release of various factors in the neighborhood of tumors [139-143]. Kurtova et al. reported that MSCs protect chronic lymphocytic leukaemic cells from apoptosis induced by fludarabine, dexamethosone, and cyclophosphamide [125]. In Fig. (2), a summary of the MSCs involvements in cancer development by above mentioned indirect effects is given. 


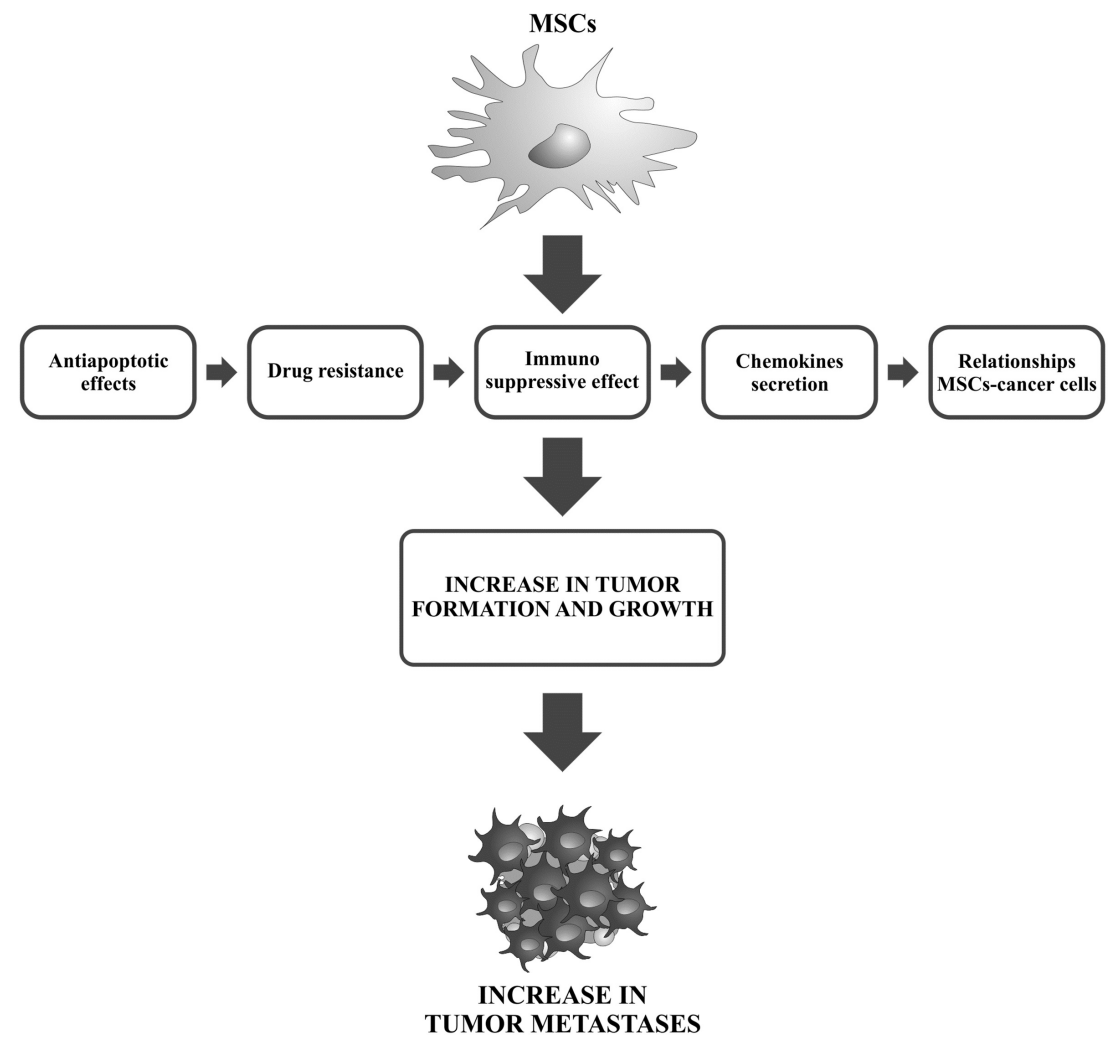

Fig. (2). Involvement of mesenchymal stem cells in cancer development by indirect effects.

With a number of target therapeutics currently under development as anticancer therapy, not only cancer cells, but also cells from the microenvironment (endothelial cells or MSCs) are targeted. This therapeutic approach may have many adverse effects associated with the elimination of cells not involved in cancer progression or in chemoresistance. There is still no confirmation of this hypothesis, and investigations are still in progress as many authors have described cells from the microenvironment which exhibit several differences with their parent cells. In one study [28]. Isolated primary glioblastoma multiforme (GBM) cells are co-cultured with MSCs and their characteristics are analyzed with cotransplantation assays. The experiment demonstrates that UCB-MSCs inhibit proliferative activity of GBM, whereas at the same time, adipose tissue-derived MSCs (AT-MSCs) support GBM proliferation. According to this study, the sources of MSCs and associated pathologies are very important for their clinical application. Parental cells (macrophages, neutrophils or MSCs) primarily possess anticancer attributes. Different MSC classes show tumor cell cytotoxicity, while others do not, which is in consensus with previous reports that proposed contradictory effects of MSCs on tumor cell proliferation $[36,59,144]$. There is a number of studies that employed cancer cell cultures and a part of them reported intensifying of cancer cell proliferation when MSCs are added $[120,121]$, and some reported recordable MSCs anticancer activity [23, 33, 34, 63, 72, 144, 145]. Conventional anticancer drug screening in vitro is typically performed in the absence of additional cells from the tumor microenvironment, which can alter obtained results about antitumor activity in vivo. Preclinical drug testing unaccompanied with experiments closely connected to tumor microenvi- ronment interactions may be a relevant explanation about the divergence in preclinical and clinical drug efficacy in cancers [146].

\section{CURRENT AND FUTURE RESEARCH AND DEVEL- OPMENTS}

An important topic in anticancer therapy are serious adverse effects of anticancer drugs on healthy tissues and in some cases dose reduction, delay of therapy or even discontinuance is needed. Toxicity for healthy tissues can be notably reduced by using a drug delivery system which selectively targets cancer cells. As a consequence, a need for more targeted anticancer therapies is obvious. A lot of researchers are in agreement that therapy based on targeted delivery is a promising tool, particularly in cancer treatments [147]. Targeted drug-delivery systems (e.g., liposomes, nano-particles) have often been proposed in an effort to reduce the side effects of toxic drugs and improve the efficacy of treating malignant diseases. This "nano-carriers" as passive-targeted drug-loaded vehicles are still the predominant delivery systems used for cancer therapy. However, these systems have limitations in their use by tumor vascularization and permeability that are largely dependent on the stage of malignancy and tumor type [148].

Most of artificial/passive drug vehicle systems used caused numerous problems, such as immune reactions and accumulation also in normal tissues, so MSCs, as cell-based active targeting vehicles, may be a possible solution. When drug resistance is an issue, MSCs can also be of importance because of the possibility to deliver more than one anticancer agent at the same time. 
One very unique and interesting approach is a novel delivery platform based on nanoghosts (NGs). NGs are produced from the whole intact cell membranes of MSCs. MSCNGs are manufactured in a reproducible process by isolating intact MSC cell membranes (ghost cells) which are homogenized into nanosized vesicles (nanoghosts) while entrapping a therapeutic of choice in the inside. The MSC-NGs retained MSC-specific in vitro and in vivo tumor targeting capabilities, hypoimmunogenicity and ability to target many kinds of cancers at different developmental stages. MSC-NGs can be made in different sizes and loaded with a variety of therapeutics, not only cell-made ones. In the study reported by Toledano Furman et al., 2013 [149], the efficacy of MSC-derived NGs against cancer was demonstrated using a prostate cancer model and by encapsulating TRAIL (the biologic model drug) insight.

Further investigations of MSCs recourses and complete understanding of specific combinations of factors controlling their tumor-specific migration and persistence will help these new technologies to be translated to clinical setting. Expanding the current knowledge about properties and mechanisms of action of MSCs associated with cancer in the ways mentioned previously, would benefit to the development of potential diagnostic, prognostic and therapeutic agents. Currently, there are about 690 clinical studies recorded by U.S. National Institutes of Health, concerning different uses of MSCs in anticancer therapy. Some of these studies are recently completed, and some of them are still in initial stages of recruiting patients. Nobody can predict how many of the proposed compositions will be registered and approved as anticancer drugs. Inconsistent results obtained in studies about MSCs themselves and on tumor cell proliferation are still of concern and should be deeply analyzed before using an MSC-based anticancer therapy. Using MSCs cannot entirely replace the conventional anticancer therapy, but can be a pathway for making a personalized therapy suitable for different cancer types.

\section{CONFLICT OF INTEREST}

The authors confirm that this article content has no conflict of interest.

\section{ACKNOWLEDGEMENTS}

Darko Bosnakovski laboratory was partially supported by AFM (2011-205/ 15380) and "FSH Society Research Fellowship Grant FSHS-82010-01".

\section{DISCLOSURE}

"Part of this article has been previously published in Recent Pat Anticancer Drug Discovery 2013 Sep; 8(3):310-8".

\section{REFERENCES}

[1] Albini A, Sporn MB. The tumour microenvironment as a target for chemoprevention. Nat Rev Cancer 2007; 7: 139-47.

[2] Zischek C, Niess H, Ischenko I, Conrad C, Huss R, Jauch KW, et al. Targeting tumor stroma using engineered mesenchymal stem cells reduces the growth of pancreatic carcinoma. Ann Surg 2009; 250(5): 747-53.
[3] Koontongkaew S. The tumor microenvironment contribution to develop-ment: Growth, invasion and metastasis of head and neck squamous cellcarcinomas, J Cancer 2013; 4(1): 66-83.

[4] Friedenstein AJ, Chailakhjan RK, Lalykina KS. The development of fibroblastcolonies in monolayer cultures of guinea-pig bone marrow and spleen cells, Cell Tissue Kinet 1970; 3 (4): 393-403.

[5] Fox JM, Chamberlain G, Ashton BA, Middleton J. Recent advances into the understanding of mesenchymal stem cell trafficking. Br J Haematol 2007; 137: 491-502.

[6] Picinich SC, Mishra PJ, Glod J, Banerjee D. The therapeutic potential of mesenchymal stem cells. Cell- \& tissue-based therapy. Expert Opin Biol Ther 2007; 7: 965-73.

[7] Bitsika V, Vlahou A, Roubelakis MG. Fetal mesenchimal stem cells in cancer therapy. Curr Stem Cell Res Ther 2013; 8(2): 13343.

[8] Pittenger MF, Mackay AM, Beck SC, Jaiswal RK, Douglas R, Mosca JD, et al. Multilineage potential of adult human mesenchymal stem cells. Science 1999; 284: 143-7.

[9] Gang EJ, Bosnakovski D, Figueiredo CA, Visser JW, Perlingeiro RC. SSEA-4 identifies mesenchymal stem cells from bone marrow. Blood 2007; 109: 1743-51.

[10] Dai LJ, Moniri MR, Zeng ZR, Zhou JX, Rayat J, Warnock GL. Potential implications of mesenchymal stem cells in cancer therapy. Cancer Lett 2011; 305(1): 8-20.

[11] Djouad F, Bouffi C, Ghannam S, Noel D, Jorgensen C. Mesenchymal stem cells: Innovative therapeutic tools for rheumatic diseases. Nat Rev Rheumatol 2009; 5: 392-9.

[12] Nombela-Arrieta C, Ritz J, Silberstein LE. The elusive nature and function of mesenchymal stem cells. Nat Rev Mol Cell Biol 2011; 12(2): 126-31.

[13] Mendes SC, Robin C, Dzierzak E. Mesenchymal progenitor cells localize within hematopoietic sites throughout ontogeny. Development 2005; 132: 1127-36.

[14] Sordi V, Malosio ML, Marchesi F, Mercalli A, Melzi R, Giordano $\mathrm{T}$, et al. Bone marrow mesenchymal stem cells express a restricted set of functionally active chemokine receptors capable of promoting migration to pancreatic islets. Blood 2005; 106: 419-27.

[15] Giordano A, Galderisi U, Marino IR. From the laboratory bench to the patient's bedside: An update on clinical trials with mesenchymal stem cells. J Cell Physiol 2007; 211: 27-35.

[16] Subramanian A, Shu-Uin G, Kae-Siang N, Gauthaman K, Biswas A, Choolani M, et al. Human umbilical cord Wharton's jelly mesenchymal stem cells do not transform to tumor-associated fibroblasts in the presence of breast and ovarian cancer cells unlike bone marrow mesenchymal stem cells. J Cell Biochem 2012; 113: 188695 .

[17] Lotfi R, Eisenbacher J, Solgi G, Fuchs K, Yildiz T, Nienhaus C, et al. Human mesenchymal stem cells respond to native but not oxidized damage associated molecular pattern molecules from necrotic (tumor) material. Eur J Immunol 2011; 41: 2021-8.

[18] Loebinger MR, Kyrtatos PG, Turmaine M, Price AN, Pankhurst Q, Lythgoe MF, Janes SM. Magnetic resonance imaging of mesenchymal stem cells homing to pulmonary metastases using biocompatible magnetic nanoparticles. Cancer Res 2009; 69(23): 8862-7.

[19] Sasportas LS, Kasmieh R, Wakimoto H, Hingtgen S, van der Water JAJM, Mohapatra G, Figueiredo JL, Martuza RL, Weissleder R, Shah K. Assessment of therapeutic efficacy and fate of engineered human mesenchymal stem cells for cancer therapy. Proc Natl Acad Sci U S A 2009; 106(12): 4822-7.

[20] Kidd S, Spaeth E, Dembinski JL, Dietrich M, Watson K, Klopp A, Battula VL, Weil M, andreeff M, Marini FC. Direct evidence of mesenchymal stem cell tropism for tumor and wounding microenvironments using in vivo bioluminescent imaging. Stem Cells 2009; 27(10): 2614-23

[21] Menon LG, Picinich S, Koneru R, Gao H, Lin SY, Koneru M, Mayer-Kuckuk P, Glod J, Banerjee D. Differential gene expression associated with migration of mesenchymal stem cells to conditioned medium from tumor cells or bone marrow cells. Stem Cells 2007; 25(2): 520-8.

[22] Moniri MR, Sun XY, Rayat J, Dai D, Ao Z, He Z, Verchere CB, Dai LJ, Warnock GL. TRAIL-engineered pancreas-derived mesenchymal stem cells: Characterization and cytotoxic effects on pancreatic cancer cells. Cancer Gene Ther 2012; 19(9): 652-8.

[23] Studeny M, Marini FC, Champlin RE, Zompetta C, Fidler IJ, Andreeff $\mathrm{M}$. Bone marrow-derived mesenchymal stem cells as vehi- 
cles for interferon-beta delivery into tumors. Cancer Res 2002; 62(13): 3603-8.

[24] Dwyer RM, Potter-Beirne SM, Harrington KA, Lowery AJ, Hennessy E, Murphy JM, Barry FP, O’Brien T, Kerin MJ. Monocyte chemotactic protein-1 secreted by primary breast tumors stimulates migration of mesenchymal stem cells. Clin Cancer Res 2007; 13: 5020-7.

[25] Chamberlain G, Fox J, Ashton B, Middleton J. Concise review: Mesenchymal stem cells: Their phenotype, differentiation capacity, immunological features, and potential for homing. Stem Cells 2007; 25: 2739-49.

[26] Gao Z, Zhang L, Hu J, Sun Y. Mesenchymal stem cells: A potential targeted-delivery vehicle for anti-cancer drug, loaded nanoparticles. Nanomedicine 2013; 9: 174-84.

[27] Karnoub AE, Dash AB, Vo AP, Sullivan A, Brooks MW, Bell GW, et al. Mesenchymal stem cells within tumour stroma promote breast cancer metastasis. Nature 2007; 449: 557-63.

[28] Akimoto K, Kimura K, Nagano M, Takano S, To'a Salazar G, Yamashita $\mathrm{T}$, et al. Umbilical cord blood-derived mesenchymal stem cells inhibit, but adipose tissue-derived mesenchymal stem cells promote, glioblastoma multiforme proliferation. Stem Cells Dev 2013; 22(9): 1370-86.

[29] Djouad F, Plence P, Bony C, Tropel P, Apparailly F, Sany J, et al. Immunosuppressive effect of mesenchymal stem cells favors tumor growth in allogeneic animals. Blood 2003; 102: 3837-44.

[30] Hall B, Dembinski J, Sasser AK, Studeny M, Andreeff M, Marini F. Mesenchymal stem cells in cancer: Tumor-associated fibroblastsand cell-based delivery vehicles. Int J Hematol 2007; 86(1): 8-16.

[31] Ren C, Kumar S, Chanda D, Chen J, Mountz JD, Ponnazhagan S. Therapeutic potential of mesenchymal stem cells producing interferon-alpha in a mouse melanoma lung metastasis model. Stem Cells 2008; 26: 2332-8.

[32] Ren C, Kumar S, Chanda D, Kallman L, Chen J, Mountz JD, et al. Cancer gene therapy using mesenchymal stem cells expressing interferon-beta in a mouse prostate cancer lung metastasis model. Gene Ther 2008; 15: 1446-53.

[33] Nakamizo A, Marini F, Amano T, Khan A, Studeny M, Gumin J, et al. Human bone marrow-derived mesenchymal stem cells in the treatment of gliomas. Cancer Res 2005; 65: 3307-18.

[34] Studeny M, Marini FC, Dembinski JL, Zompetta C, CabreiraHansen M, Bekele BN, et al. Mesenchymal stem cells: Potential precursors for tumor stroma and targeted-delivery vehicles for anticancer agents. J Natl Cancer Inst 2004; 96: 1593-603.

[35] Chen XC, Wang R, Zhao X, Wei YQ, Hu M, Wang YS, et al. Prophylaxis against carcinogenesis in three kinds of unestablished tumor models via IL12-gene-engineered MSCs. Carcinogenesis 2006; 27: 2434-41.

[36] Nakamura K, Ito Y, Kawano Y, Kurozumi K, Kobune M, Tsuda H, et al. Antitumor effect of genetically engineered mesenchymal stem cells in a rat glioma model. Gene Ther 2004; 11: 1155-64.

[37] Xin H, Kanehira M, Mizuguchi H, Hayakawa T, Kikuchi T, Nukiwa T, et al. Targeted delivery of CX3CL1 to multiple lung tumors by mesenchymal stem cells. Stem Cells 2007; 25: 1618-26.

[38] Lens M. Cutaneous melanoma: interferon alpha adjuvant therapy for patients at high risk for recurrent disease. Dermatol Ther 2006; 19(1): 9-18.

[39] Dong Z, Greene G, Pettaway C, Dinney CP, Eue I, Lu W, Bucana CD, Balbay MD, Bielenberg D, Fidler IJ. Suppression of angiogenesis, tumorigenicity, and metastasis by human prostate cancer cells engineered to produce interferon-beta, Cancer Res 1999; 59(4): 872-9.

[40] Qin XQ, Runkel L, Deck C, DeBios C, Barsoum J. Interferon-beta induces $\mathrm{S}$ phase accumulation selectively in human transformed cells. J Interferon Cytokine Res 1997; 17(6): 355-67.

[41] Streck CJ, Dickson PV, Ng CY, Zhou J, Hall MM, Gray JT, Nathwani AC, Davidoff AM. Antitumor efficacy of AAV-mediated systemic delivery of interferon-beta, Cancer Gene Ther 2006; 13(1): 99-106.

[42] Eliopoulos N, Francois M, Boivin MN, Martineau D, Galipeau J. Neo-organoid of marrow mesenchymal stromal cells secreting interleukin-12 for breast cancer therapy. Cancer Res 2008; 68: 48108 .

[43] Chen X, Lin X, Zhao J, Shi W, Zhang H, Wang Y, et al. A tumorselective biotherapy with prolonged impact on established metastases based on cytokine gene-engineered MSCs. Mol Ther 2008; 16: 749-56.
[44] Stagg J, Lejeune L, Paquin A, Galipeau J. Marrow stromal cells for interleukin-2 delivery in cancer immunotherapy. Hum Gene Ther 2004; 15: 597-608

[45] Schoenhaut DS, Chua AO,Wolitzky AG, Quinn PM, Dwyer CM, McComas W, Familletti PC, Gately MK, Gubler U. Cloning and expression of murine IL-12. J Immunol 1992; 148(11): 3433-40.

[46] Samant RS, Shevde LA. Recent advances in anti-angiogenic therapy of cancer. Oncotarget 2011;2(3): 122-34.

[47] Corsten MF, Shah K. Therapeutic stem-cells for cancer treatment: Hopes and hurdles in tactical warfare. Lancet Oncol 2008; 9(4): 376-84.

[48] van Eekelen M, Sasportas L, Kasmieh R, Yip S, Figueiredo J-L, Louis DN, Weissleder R, Shah K. Human stem cells expressing novel TSP-1 variant have anti-angiogenic effect on brain tumors. Oncogene 2010; 29(22): 3185-95.

[49] Shah K. Mesenchymal stem cells engineered for cancer therapy. Adv Drug Deliv Rev 2012; 64(8): 739-48

[50] Komarova S, Kawakami Y, Stoff-Khalili MA, Curiel DT, Pereboeva L. Mesenchymal progenitor cells as cellular vehicles for delivery of oncolytic adenoviruses. Mol Cancer Ther 2006; 5: 755-66.

[51] Hakkarainen T, Särkioja M, Lehenkari P, Miettinen S, Ylikomi T, Suuronen R, et al. Human mesenchymal stem cells lack tumor tropism but enhance the antitumor activity of oncolytic adenoviruses in orthotopic lung and breast tumors. Hum Gene Ther 2007; 18 : 627-41.

[52] Stoff-Khalili MA, Rivera AA, Mathis JM, Banerjee NS, Moon AS, Hess A, et al. Mesenchymal stem cells as a vehicle for targeted delivery of CRAds to lung metastases of breast carcinoma. Breast Cancer Res Treat 2007; 105: 157-67.

[53] Dembinski JL, Spaeth EL, Fueyo J, Gomez-Manzano C, Studeny $\mathrm{M}$, Andreeff $\mathrm{M}$, et al. Reduction of nontarget infection and systemic toxicity by targeted delivery of conditionally replicating viruses transported in mesenchymal stem cells. Cancer Gene Ther 2010; 17: 289-97.

[54] Nakashima H, Kaur B, Chiocca EA. Directing systemic oncolytic viral delivery to tumors via carrier cells. Cytokine Growth Factor Rev 2010; 21(2-3): 119-26.

[55] Bergelson JM, Cunningham JA, Droguett G, Kurt-Jones EA, Krithivas A, Hong JS, et al. Isolation of a common receptor for Coxsackie B viruses and adenoviruses 2 and 5. Science 1997; 275: 1320-3.

[56] Xiong Z, Cheng Z, Zhang X, Patel M, Wu JC, Gambhir SS, et al. Imaging chemically modified adenovirus for targeting tumors expressing integrin alphavbeta3 in living mice with mutant herpes simplex virus type 1 thymidine kinase PET reporter gene. J Nucl Med 2006; 47: 130-9.

[57] Lamfers M, Idema S, van Milligen F, Schouten T, van der Valk P, Vandertop $\mathrm{P}$, et al. Homing properties of adipose-derived stem cells to intracerebral glioma and the effects of adenovirus infection. Cancer Lett 2009; 274: 78-87.

[58] Menotti L, Cerretani A, Hengel H, Campadelli-Fiume G. Construction of a fully retargeted herpes simplex virus 1 recombinant capable of entering cells solely via human epidermal growth factor receptor 2. J Virol 2008; 82: 10153-61.

[59] Uchibori R, Okada T, Ito T, Urabe M, Mizukami H, Kume A, et al. Retroviral vector-producing mesenchymal stem cells for targeted suicide cancer gene therapy. J Gene Med 2009; 11:373-81.

[60] Kucerova L, Matuskova M, Pastorakova A, Tyciakova S, Jakubikova J, Bohovic R, et al. Cytosine deaminase expressing human mesenchymal stem cells mediated tumour regression in melanoma bearing mice. J Gene Med 2008; 10: 1071-82.

[61] Matuskova M, Hlubinova K, Pastorakova A, Hunakova L, Altanerova $\mathrm{V}$, Altaner $\mathrm{C}$, et al. HSV-tk expressing mesenchymal stem cells exert bystander effect on human glioblastoma cells. Cancer Lett 2010; 290: 58-67.

[62] Zischek C, Niess H, Ischenko I, Conrad C, Huss R, Jauch KW, et al. Targeting tumor stroma using engineered mesenchymal stem cells reduces the growth of pancreatic carcinoma. Ann Surg 2009; 250: 747-53

[63] Hamada H, Kobune M, Nakamura K, Kawano Y, Kato K, Honmou $\mathrm{O}$, et al. Mesenchymal stem cells (MSC) as therapeutic cytoreagents for gene therapy. Cancer Sci 2005; 96: 149-56.

[64] Kucerova L, Altanerova V, Matuskova M, Tyciakova S, Altaner C. Adipose tissue-derived human mesenchymal stem cells mediated prodrug cancer gene therapy. Cancer Res 2007; 67: 6304-13. 
[65] Both GW. Gene-directed enzyme prodrug therapy for cancer: A glimpse into the future? Discov Med 2009; 8(42): 97-103.

[66] Altaner C. Prodrug cancer gene therapy. Cancer Lett 2008; 270 : 191-201.

[67] Hong I-S, Lee H-Y, Kang K-S. Mesenchymal stem cells and cancer: Friends or enemies? Mutat Res Fundam Mol Mech Mutagen 2014; 768: 98-106.

[68] Loebinger MR, Eddaoudi A, Davies D, Janes SM. Mesenchymal stem cell delivery of TRAIL can eliminate metastatic cancer. Cancer Res 2009; 69: 4134-42.

[69] Kim SW, Kim SJ, Park SH, Yang HG, Kang MC, Choi YW, et al. Complete regression of metastatic renal cell carcinoma by multiple injections of engineered mesenchymal stem cells expressing dodecameric TRAIL and HSV-TK. Clin Cancer Res 2013; 19: 415-27.

[70] Benedetti S, Pirola B, Pollo B, Magrassi L, Bruzzone MG, Rigamonti $\mathrm{D}$, et al. Gene therapy of experimental brain tumors using neural progenitor cells. Nat Med 2000; 6: 447-50.

[71] Mohr A, Lyons M, Deedigan L, Harte T, Shaw G, Howard L, et al. Mesenchymal stem cells expressing TRAIL lead to tumour growth inhibition in an experimental lung cancer model. J Cell Mol Med 2008; 12: 2628-43.

[72] Kim SM, Lim JY, Park SI, Jeong CH, Oh JH, Jeong M, et al. Gene therapy using TRAIL-secreting human umbilical cord bloodderived mesenchymal stem cells against intracranial glioma. Cancer Res 2008; 68: 9614-23.

[73] Wiley SR, Schooley K, Smolak PJ, Din WS, Huang CP, Nicholl $\mathrm{JK}$, et al. Identification and characterization of a new member of the TNF family that induces apoptosis. Immunity $1995 ; 3(6)$ : $673-$ 82.

[74] Mueller LP, Luetzkendorf J, Widder M, Nerger K, Caysa H, Mueller T. TRAIL-transduced multipotent mesenchymal stromal cells (TRAIL-MSC) overcome TRAIL resistance in selected CRC cells in vitro and in vivo. Cancer Gene Ther 2011; 18: 229-39.

[75] Pittenger, M.E., Aggarwal, S. Mesenchymal stem cells and uses therefor. US20110142807 (2011).

[76] Aggarwal, S., Pittenger, M.F., Varney, T. Mesenchymal stem cells and uses therefor. US2014016776 (2014).

[77] Crawford, K.D., Southgate, C. Multipotent stem cells and uses thereof. US8574567 (2013).

[78] Brodie, C., Slavin, S. Mesenchymal stem cells for in vitro modeling and cell-based therapy of human diseases and banks thereof. WO2013124815 (2013).

[79] Peled, T., Steinhardt, K-S. Methods of culturing and expanding mesenchymal stem cells and isolated cell populations generated thereby. US20140023623 (2014).

[80] Sabbadini, R.A. Stem cell therapy using inhibitors of lysophosphatidic acid. WO2013023040 (2013).

[81] Lim, S.K., Lye, E. Method of deriving mesenchymal stem cells. US20150197725 (2015).

[82] Betancourt, A.M. Mesenchymal stem cells and related therapies. WO2012051210 (2012).

[83] Betancourt, A.M. Mesenchymal stem cells and related therapies. US20140017787 (2014).

[84] Cheng, Z., Chen, K., Chen, X. Imaging-aided gene therapy using mesenchymal stem cells as target-delivery vehicle. WO2013158962 (2013).

[85] Cheng, Z., Chen, K., Chen, X. Imaging-aided gene therapy using mesenchymal stem cells as target-delivery vehicle. US20150086515 (2015).

[86] Wang, X., Xu, R-H. Mesenchymal-like stem cells derived from human embryonic stem cells, methods and uses thereof. WO2014011407 (2014) \& WO2014011881 (2014).

[87] Chang, J.W., Kim, D.S., Yang, Y-S., Oh, W. Composition for the diagnosis, prevention or treatment of disease related to cells expressing IL-8 or GRO-alpha, comprising UCB-MSCs. US20130189189 (2013).

[88] Janes, S.M., Lythgoe, M.F., Pankhurst, Q. Use of nanoparticles for the treatment of cancer. US20120010499 (2012).

[89] Chang, J.W., Kim, D.S., Yang, Y-S., Oh, W. UCB-MSC comprising a tumor suppressor gene reduce the size of an IL-8 or GRO- $\alpha$ expressing tumor. US8506948 (2013).

[90] Deng, W.-P., Chang, H.-K., Wei, H.-C., Wu, T.-H.A. Combination of protein vaccine and mesenchymal stem cells for treating cancer. US20110027311 (2011).

[91] Wei HJ, Wu AT, Hsu CH, Lin YP, Cheng WF, Su CH, et al. The development of a novel cancer immunotherapeutic platform using tumor-targeting mesenchymal stem cells and a protein vaccine. Mol Ther 2011; 19: 2249-57.

[92] Markovic, S.N. Treating cancer. US20140056909 (2014).

[93] Cohen, S. Pharmaceutical compositions and methods for the treatment and prevention of cancer. US20130052272 (2013).

[94] Habib, N.A., Gordon, M. Medium derived from stem cells as a pharmaceutical composition. US8652846 (2014).

[95] Lim, S.K. Mesenchymal stem cells particles. US20150190430 (2015).

[96] Bourbeau D, Lau CJ, Jaime J, Koty Z, Zehntner SP, Lavoie G, et al. Improvement of antitumor activity by gene amplification with a replicating but nondisseminating adenovirus. Cancer Res 2007; 67: 3387-95.

[97] Bourbeau D, Lavoie G, Nalbantoglu J, Massie B. Suicide gene therapy with an adenovirus expressing the fusion gene CD: UPRT in human glioblastomas: Different sensitivities correlate with p53 status. J Gene Med 2004; 6: 1320-32.

[98] Chang D-Y, Yoo S-W, Hong Y, Kim S, Kim SY, Yoon S-H, et al. The growth of brain tumors can be suppressed by multiple transplantation of mesenchymal stem cells expressing cytosine deaminase. Int J Cancer 2010; 127: 1975-83.

[99] Miletic H, Fischer Y, Litwak S, Giroglou T, Waerzeggers Y, Winkeler A, et al. Bystander killing of malignant glioma by bone marrow-derived tumor-infiltrating progenitor cells expressing a suicide gene. Mol Ther 2007; 15: 1373-81.

[100] Nelson, P.J. Engineered mesenchymal stem cells and method of using same to treat tumors. US20120087901 (2012).

[101] Li, G., Lee, Y.W., Lau, P.Y. Cell-mediated gene therapy for cancer using mesenchymal stem cells expressing a suicide gene. US20130171115 (2013).

[102] Orrichio, E., Wendel, H-G. Cancer-specific suicide gene for cellbased and gene therapy. WO2013106774 (2013).

[103] Pereboeva L, Komarova S, Mikheeva G, Krasnykh V, Curiel DT. Approaches to utilize mesenchymal progenitor cells as cellular vehicles. Stem Cells 2003; 21: 389-404.

[104] Boyan, B.D., Schwartz, Z., Lee, C.S.D., Leslie, S.K., Kinney, R.C. Protein delivery from stem cell microcarriers. WO2012071527 (2012).

[105] Studeny, M., Andreeff, M., Marini, F.C. Local production and/or delivery of anti-cancer agents by stromal cell precursors. US20040076622 (2004)

[106] Von Laer, D., Heimann, T. LCMV-GP-VSV-pseudotyped vectors and tumor-infiltrating virus-producing cells for the therapy of tumors. US20110250188 (2011).

[107] Ra, J.C., Kang, S.K., Woo, S.K., Youn, H.Y., Lee, H.W., Seo, K.W. Anti-tumor composition comprising human-derived adult stem cells. US20120263685 (2012).

[108] Prockop, D.J., Lee, R.H., Yoon, N., Reneau, J., Berkowitz, B.A. Treatment of tumors with activated mesenchymal stem cells. WO2014066122 (2014).

[109] Grisendi G, Bussolari R, Cafarelli L, Petak I, Rasini V, Veronesi E, et al. Adipose-derived mesenchymal stem cells as stable source of tumor necrosis factor-related apoptosis-inducing ligand delivery for cancer therapy. Cancer Res 2010; 70: 3718-29.

[110] Szegezdi E, O'Reilly A, Davy Y, Vawda R, Taylor DL, Murphy M, et al. Stem cells are resistant to TRAIL receptor-mediated apoptosis. J Cell Mol Med 2009; 13: 4409-14.

[111] Ashkenazi A. Directing cancer cells to self-destruct with proapoptotic receptor agonists. Nat Rev Drug Discov 2008; 7: 1001-12.

[112] Hotte SJ, Hirte HW, Chen EX, Siu LL, Le LH, Corey A, et al. A phase 1 study of mapatumumab (fully human monoclonal antibody to TRAIL-R1) in patients with advanced solid malignancies. Clin Cancer Res 2008; 14: 3450-5.

[113] Kim SM, Woo JS, Jeong CH, Ryu CH, Lim JY, Jeun SS. Effective combination therapy for malignant glioma with TRAIL-secreting mesenchymal stem cells and lipoxygenase inhibitor MK886. Cancer Res 2012; 72: 4807-17.

[114] Shah, K. Multimodal TRAIL molecules and uses in cellular therapies. WO2012106281 (2012).

[115] The General Hospital Corporation. Multimodal TRAIL molecules and uses in cellular therapies. US20140086907 (2014).

[116] Sung Y.C., Kim S.W., Kim S.J., Park S.H. Vector simultaneously expressing dodecameric TRAIL and HSV-TK suicide genes, and anticancer stem cell therapeutic agent using same. US20140369979 (2014). 
[117] Shah, K. Stem cell delivered oncolytic herpes simplex virus and methods for treating brain tumors. WO2015089280 (2015).

[118] Chang, A., Nolta, J. Mesenchymal stem cells for targeted cancer therapy. WO2015100268 (2015).

[119] Klopp AN, Gupta A, Spaeth E, Andreeff M, Marini F. Concise review: Dissecting a discrepancy in the literature: Do mesenchymal stem cells support or suppress tumor growth? Stem Cells 2011;29: $11-9$.

[120] Zhu W, Xu W, Jiang R, Qian H, Chen M, Hu J, et al. Mesenchymal stem cells derived from bone marrow favor tumor cell growth in vivo. Exp Mol Pathol 2006; 80: 267-74.

[121] Yu JM, Jun ES, Bae YC, Jung JS. Mesenchymal stem cells derived from human adipose tissues favor tumor cell growth in vivo. Stem Cells Dev 2008; 17: 463-73.

[122] Serakinci N, Fahrioglu U, Christensen R. Mesenchymal stem cells, cancer challenges and new directions. Eur J Cancer 2014; 50: 1522-30.

[123] Li L, Tian H, Yue WM, Zhu F, Li SH, Li W.J. Human mesenchymal stem cells play a dual role on tumor cell growth in vitro and in vivo. J Cell Physiol 2011; 226(7): 1860-7.

[124] Kucerova L, Matuskova M, Hlubinova K, Altanerova V, Altaner C. Tumor cell behaviour modulation by mesenchymal stromal cells. Mol Cancer 2010; 9: 129.

[125] Kurtova AV, Balakrishnan K, Chen R, Ding W, Schnabl S, Quiroga MP, et al. Diverse marrow stromal cells protect CLL cells from spontaneous and drug-induced apoptosis: Development of a reliable and reproducible system to assess stromal cell adhesionmediated drug resistance. Blood 2009; 114(20): 4441-50.

[126] Wang XF, Zhang ZQ, Yao C. Survivin is upregulated in myeloma cell lines cocultured with mesenchymal stem cells. Leukemia Res 2010; 34 (10): 1325-9.

[127] Patel SA, Meyer JR, Greco SJ, Corcoran KE, Bryan R, Rameshwar P. Mesenchymal stem cells protect breast cancer cells through regulatory T cells: Role of mesenchymal stem cell-derived TGF- $\beta$. J Immunol 2010; 184(10): 5885-94.

[128] Lazennec G, Jorgensen C. Adult multipotent stromal cells and cancer: risk or benefit? Stem Cells 2008; 26: 1387-94.

[129] Maestroni GJ, Hertens E, Galli P. Factor(s) from nonmacrophage bone marrow stromal cells inhibit Lewis lung carcinoma and B16 melanoma growth in mice. Cell Mol Life Sci 1999; 55: 663-7.

[130] Fierro FA, Sierralta WD, Epuñan MJ, Minguell JJ. Marrow-derived mesenchymal stem cells: Role in epithelial tumor cell determination. Clin Exp Metastasis 2004; 21: 313-9.

[131] Gunn WG, Conley A, Deininger L, Olson SD, Prockop DJ, Gregory CA. A crosstalk between myeloma cells and marrow stromal cells stimulates production of Dkk1 and interleukin-6: a potential role in the development of lytic bone disease and tumor progression in multiple myeloma. Stem Cells 2006; 24: 986-91.

[132] Serakinci N, Christensen R, Fahrioglu U, Sorensen FB, DagnaesHansen F, Hajek M, et al. Mesenchymal stem cells as therapeutic delivery vehicles targeting tumor stroma. Cancer Biother Radiopharm 2011; 26(6): 767-73.

[133] Le Blanc K, Ringdén O. Immunobiology of human mesenchymal stem cells and future use in hematopoietic stem cell transplantation. Biol Blood Marrow Transplant 2005; 11(5): 321-34.
[134] Pasquet M, Golzio M, Mery E, Rafii A, Benabbou N, Mirshahi P, et al. Hospicells (ascites-derived stromal cells) promote tumorigenicity and angiogenesis. Int J Cancer 2010; 9: 2090-101.

[135] Poggi A, Mussoa A, Dapinoa I, Zocchi MR. Mechanisms of tumor escape from immune system: Role of mesenchymal stromal cells. Immunol Lett 2014; 159: 55-72.

[136] Voloshin T, Fremder E, Shaked Y. Small but mighty: Microparticles as mediators of tumor progression. Cancer Microenviron 2014; 7: 11-21.

[137] Banerjee, D., Mishra, P.J., Mishra, P.J., Gao, H., Glod, J. Reconstituted tumor microenvironment for anticancer drug development. US20120213706 (2012).

[138] Derr, A.G., Weaver, D.T., Shapiro, I., Paterson, D.W., Pachter, J. The biomarkers for cancer stem cell and related methods of use. WO2013134649 (2013).

[139] Roodhart JM, Daenen LG, Stigter EC, Prins HJ, Gerrits J, Houthuijzen JM, et al. Mesenchymal stem cells induce resistance to chemotherapy through the release of platinum-induced fatty acids. Cancer Cell 2011; 3: 370-83.

[140] Hao M, Zhang L, An G, Meng H, Han Y, Xie Z, et al. Bone marrow stromal cells protect myeloma cells from bortezomib induced apoptosis by suppressing microRNA-15a expression. Leuk lymphoma 2011; 9: 1787-94.

[141] Jin L, Tabe Y, Konoplev S, Xu Y, Leysath CE, Lu H, et al. CXCR4 up-regulation by imatinib induces chronic myelogenous leukemia (CML) cell migration to bone marrow stroma and promotes survival of quiescent CML cells. Mol Cancer Ther 2008; 1 : 48-58.

[142] Castells M, Thibault B, Mery E, Golzio M, Pasquet M, Hennebelle $\mathrm{I}$, et al. Ovarian ascites-derived Hospicells promote angiogenesis via activation of macrophages. Cancer Lett 2012; 326: 59-68.

[143] Castells M, Thibault B, Delord J-P, Couderc B. Implication of tumor microenvironment in chemoresistance: Tumor-associated stromal cells protect tumor cells from cell death. Int J Mol Sci 2012; 13: 9545-71.

[144] Ciavarella S, Dominici M, Dammacco F, Silvestris F. Mesenchymal stem cells: A new promice in anticancer therapy. Stem Cell Dev 2011; 20: 1-10.

[145] Hong X, Miller C, Savant-Bhonsale S, Kalkanis SN. Antitumor treatment using interleukin-12-secreting marrow stromal cells in an invasive glioma model. Neurosurgery 2009; 64: 1139-47.

[146] Hanahan D, Coussens LM. Accessories to the crime: Functions of cells recruited to the tumor microenvironment. Cancer Cell 2012; 3: 309-22.

[147] Gjorgieva D, Zaidman N, Bosnakovski D. Mesenchymal stem cells for anti-cancer drug delivery. Recent Pat Anticancer Drug Discov 2013; 8(3): 310-8.

[148] Yu MK, Park J, Jon S. Targeting strategies for multifunctional nanoparticles in cancer imaging and therapy. Theranostics 2012; 2(1): 3-44.

[149] Toledano Furman NE, Lupu-Haber Y, Bronshtein T, Kaneti L, Letko N, Weinstein E, et al. Reconstructed stem cell nano-ghosts: A natural tumor targeting platform. Nano Lett 2013; 13: 3248-55. 